\title{
Measurement and modeling of wind waves at the northern coast of Santa Catarina, Brazil
}

\author{
José Henrique G. M. Alves \& Eloi Melo
}

\author{
Laboratório de Hidráulica Marítima, UFSC \\ Programa de Pós-Graduação, Engenharia Ambiental \\ (Caixa Postal 5039, 88040-970 Campus Trindade, Florianópolis, SC, Brasil)
}

- Abstract: Directional measurements of wind-wave spectra made during the year of 1996 are used in a preliminary investigation of the wind-wave climate and its transformation at the São Francisco do Sul island, northern coast of the Santa Catarina state. Four major sea states and associated meteorological conditions are identified through analyses of joint distributions of observed wave parameters. Transformations of these main sea-state patterns due to refraction and shoaling are investigated through a numerical modeling approach that allows the reconstruction of the wave field within extensive coastal areas, using single point measurements of the wave spectrum in shallow waters. Cross-validation of measured and reconstructed spectra at the study site yield consistent results, suggesting that the proposed methodology works well for the São Francisco do Sul coast.

- Resumo: Medições do espectro direcional de ondas geradas pelo vento realizadas em 1996 são utilizadas em uma investigação preliminar do clima de ondas no litoral norte de Santa Catarina, Brasil. Quatro estados de mar predominantes são identificados, em conjunto com os padrões meteorológicos associados a sua ocorrência, através de análises estatísticas. As transformações desses quatro estados de mar devido a refração e empinamento são investigadas através de modelos numéricos, que permitem obter estimativas do campo de ondas em áreas extensas a partir de medições pontuais feitas em águas rasas. Comparações entre espectros medidos e modelados produzem resultados consistentes, sugerindo que a metodologia proposta é válida para a costa de São Francisco do Sul.

- Descriptors: Wind-waves, Spectral wave refraction, Numerical models, Wave climate.

- Descritores: Propagação de ondas oceânicas de vento, Refração espectral, Modelos numéricos, Clima de ondas.

\section{Introduction}

The island of São Francisco do Sul in Santa Catarina is a popular beach resort well known for its pristine beaches which attract tourists engaged in nautical sports and other recreational activities. Besides tourism related enterprises, the island also shelters a maritime facility operated by Companhia de Petróleo Brasileiro S/A. (PETROBRAS). The facility consists of several inland storage tanks connected through an underwater duct to a large offshore buoy where oil tankers anchor to unload their cargo. A small port was also built around Enseada Headland to provide support for sea operations (see Fig. 1).

In 1996, environmental issues concerning the operation of this facility led PETROBRAS to sponsor a comprehensive field measurement campaign intended to collect oceanographic and meteorological data in the area. This campaign, carried out by the Federal University of Santa Catarina, included measurements of waves, currents, tides, sea-water temperature and salinity and several meteorological parameters near the PETROBRAS facility. 
Our work reports some preliminary results derived from the wave measurements performed at the São Francisco do Sul coast. The objectives are to identify the main sea-state regimes off São Francisco do Sul Island and to validate a method to obtain deep-water estimates of wave spectra measured close to the coast using numerical modeling. The innovative aspects of this work include a first contribution towards wave-climate studies using directional wave measurements made at southern Brazil, and the use of a back-refraction wave model to investigate the transformation of wave spectra.

We begin in section 2 by describing the instrument used for the wave measurements and by giving a brief outline of the techniques used for data analysis and interpretation. Next, in section 3, we present some preliminary results on the main sea-state regimes found in the area. A methodology for extrapolating single-point shallowwater wave measurements to a large coastal area is described in section 4. It consists of a backrefraction model that is used to produce estimates of the wave field in deep water, combined with a second wave model used to forward-refract the deep-water spectra towards an extense area in the vicinity of the measurement site. In section 5, this back- and forward-refraction approach is used to investigate the impact of bottom refraction on wave spectra transformation at the São Francisco do Sul coast. Concluding remarks are made in section 6 .

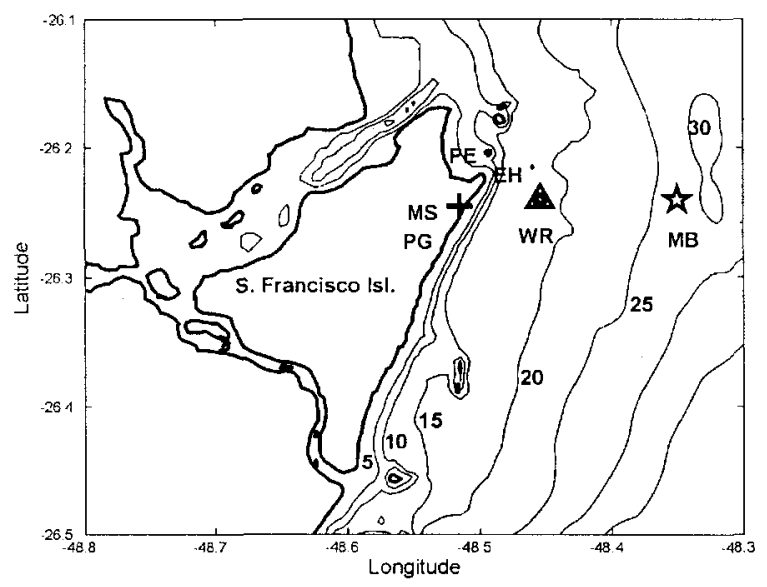

Fig. 1. Location of the study site at São Francisco do Sul Island. The positions of the Enseada Beach (PE) and Headland $(\mathrm{EH})$, of the Waverider buoy (triangle labeled WR), of the meteorological station (cross labeled MS), of Praia Grande (PG) extending southwest from Enseada Headland and of the offshore docking buoy operated by PETROBRAS (star labeled $\mathrm{MB}$ ) are indicated. Depth contours are indicated at five-meter intervals.

\section{Wave measurements}

Measurements of directional wind-wave spectra were performed by the Marine Hydraulics Laboratory (Laboratório de Hidráulica Marítima LaHiMar), of the Federal University of Santa Catarina (UFSC) at São Francisco do Sul during 1996. Wave observations were made with a Datawell Directional Waverider deployed $1.5 \mathrm{~km}$ offshore from Praia Grande at a depth of approximately $20 \mathrm{~m}$ (Fig. 1). The Waverider is a spherical buoy of $0.9 \mathrm{~m}$ diameter containing an inertia stabilized platform equipped with three accelerometers oriented orthogonally in one vertical and two horizontal directions from which vertical and horizontal (eastward and northward) displacements are obtained. Data were transmitted from the buoy by radio and stored in a computer installed in a land-based facility in Praia Grande.

Wave measurements started on January 1996 and lasted till September 1996, when the Waverider buoy was dragged to the shore during a storm. The Waverider was set to measure 20-minute-long records eight times a day at three hour intervals. A total of 930 records were obtained over a period of eight months. Due to the remote location of the land-based data-storage facility, problems with power supply and other logistical mishaps caused loss of data during part of February and March and, unfortunately, during the whole month of July and parts of June and September.

Waverider buoy measurements consist of a set of three independent time series of sea surface displacements,

$$
X(t)=X_{z}(t), X_{N}(t), X_{k}(t)
$$

where $X_{z}$ refers to the vertical elevation and $X_{N}$ and $X_{L}$ to the north $(\mathrm{N})$ and east (E) horizontal displacements. According to the manufacturer Datawell, measurements made with the Directional Waverider have a resolution of $1 \mathrm{~cm}$ for measurements of the vertical displacement $X_{z}$ and a directional resolution of $1.5^{\circ}$.

Directional spectra at the measurement site were obtained from cross spectra calculated from the time series (1) using the Welch method with 32 degrees of freedom and $25 \%$ overlap between segments. Details of the analysis techniques are beyond the scope of the present work. The interested reader is referred to Alves \& Melo (1999) for a recent review of the subject.

Directional wave spectra provide a complete description of a given sea state and are useful for calculating the transformations of the wave field as it propagates to the shore (see section 4). However, it is 
still common practice to characterize a sea state in simpler terms by means of the following three parameters: (i) the significant wave height $H_{s}$, (ii) the peak period $T_{p}$ and (iii) the dominant direction $\theta_{m}$

The significant wave height $H_{s}$ represents the average of the highest $1 / 3$ of all waves from an arbitrary wave field. This parameter has historical significance, as it appeared to correlate well with visual estimates of wave height made by experienced observers. According to Longuet-Higgins (1952), individual wave heights are random variables that follow closely the Rayleigh statistical distribution. Consequently, $H_{s}$ may be derived from the total energy or variance of the wave field, and thus the wave spectrum, as follows:

$$
H_{s}=4 m_{0}^{1 / 2}
$$

with the total energy $m_{0}$ calculated by integration of the one-dimensional frequency spectrum $S(\omega)$

$$
m_{0}=\int_{0}^{\omega_{\max }} S(\omega) d \omega
$$

where $\omega_{\max }=\pi \Delta t$ is a limiting frequency.

The peak period $T_{p}=2 \pi / \omega_{p}$ corresponds to the frequency with the highest energy density present in $S(\omega)$

The dominant direction $\theta_{m}$ is calculated from (Longuet-Higgins, 1963)

$\theta_{m}=\tan ^{-1} \frac{Q_{z l i}}{Q_{z N}}$

where $Q_{z N}$ and $Q_{z /}$ are the quadrature spectra of $X_{z}(t)$ with $\mathrm{X}_{\mathrm{N}}(\mathrm{t})$ and $\mathrm{X}_{\mathrm{E}}(\mathrm{t})$, given by

$$
\begin{aligned}
& Q_{z N}(\omega)=k \int_{0}^{2 \pi} E(\omega, \theta) \cos (\theta) d \theta \\
& Q_{z k}(\omega)=k \int_{0}^{2 \pi} E(\omega, \theta) \operatorname{sen}(\theta) d \theta
\end{aligned}
$$

where $\theta$ is the direction of propagation of individual spectral components and $E(\omega, \theta)$ is the twodimensional frequency-directional spectrum, defined in terms of $S(\omega)$ as

$$
E(\omega, \theta)=S(\omega) D(\omega, \theta)
$$

In the previous equation, $D(\omega, \theta)$ is a directional spreading function. In our study, $D(\omega, \theta)$ is determined according to a model-free formulation described in details by Alves \& Melo (1999).

Synoptic properties of the wind fields over the South Atlantic Ocean during the campaign, an important piece of information for identifying the typical sea states, were inferred from the analysis of atmospheric surface pressure charts made available by the Brazilian Navy. Information on the local wind speed and direction, collected by an automatic meteorological station as indicated in Figure 1, was also used in the analysis. Although the length of the wave measurement campaign fell short of what was initially intended, we believe that the available data were long enough to identify the main wave patterns expected to exist in the area, as supported by evidence discussed in the next section.

\section{Main sea-state regimes}

A good starting point for understanding some basic features of the waves at São Francisco do Sul is to find out what regions of the ocean may act as sources of waves for this area. Through a simple inspection of a world map and recalling that swell waves propagate across the oceans along great circle routes, one sees that the major wave source area for that part of our littoral is the South Atlantic Ocean. In fact, the broad shape of the northeastern part of the South American continent prevents swell generated in the North Atlantic from reaching the southern shores of Brazil.

Furthermore, despite the existence of a large "window" to the Indian Ocean between southern Africa and Antarctica, swell from that ocean would be a nearly negligible contribution to the wave climate of South America because those waves would have to propagate from the east, against the dominant wind and storm directions. Swell from the Pacific coming through the Drake Passage must also be ruled out since no great circle can reach the coast of Brazil from that window, as shown by Alves (1991).

Winds over the South Atlantic are highly influenced by the existence of a semi-permanent high-pressure system centered over the ocean. The eastern branch of the associated anti-cyclonic gyre gives rise to fairly persistent winds from the northeast along the southeastern and southern coasts of Brazil. This basic pattern, however, is regularly disturbed by the passage of cold fronts that typically travel along the coast towards the northeast. The passage of such disturbances is accompanied by migrating high and low pressure centers which perturb the basic air flow producing significant winds and waves from the south and east quadrants.

As Taljaard (1967), Nimer (1989) and Lima \& Satyamurti (1992) have pointed out, meteorological patterns over the southern Brazilian coast occur with great regularity all year round regardless of seasonality. Seasonal differences appear to affect the intensity and frequency of these systems rather than their characteristics. This observation is in 
accordance with a remarkable feature of the South Atlantic weather system, namely, the total absence of hurricanes and tropical storms over the tropical ocean. In fact, as opposed to its northern counterpart, the South Atlantic Ocean experiences no hurricane season and, consequently, no hurricane-generated waves.

The basic environmental features pointed out above encouraged us to regard the somewhat limited data set that we have at our disposal as representative for the main sea states expected to exist at the study site. A summary of the available measurements is presented in Figure 2, showing time series of the characteristic sea-state parameters $H_{s}, T_{p}$ and $\theta_{m}$, along with the maximum recorded wave height $H_{\max }$ and local wind speed and direction at $10 \mathrm{~m}$ height, $U_{10}$ and $\theta_{l j}$. We note first that the restrictions imposed by the orientation of the coastline confine the dominant direction $\theta_{m}$ to a sector between $174^{\circ}$ (approximately south) and $40^{\circ}$ (approximately northeast).

(a)

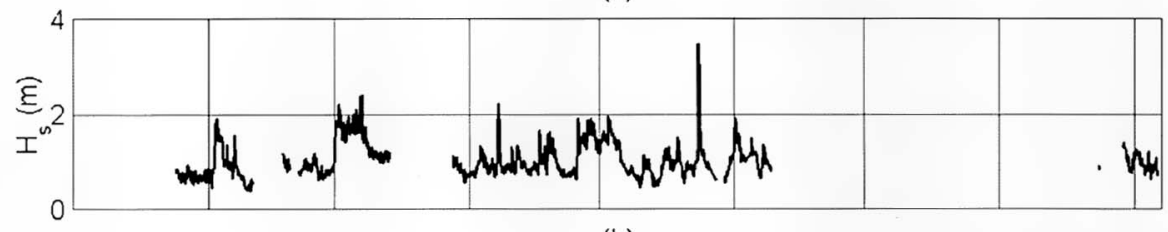

(b)

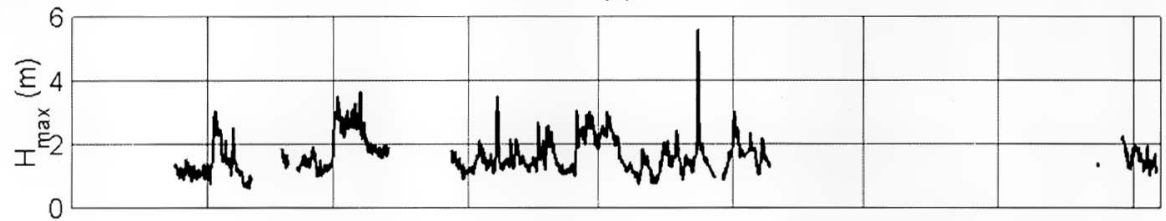

(c)

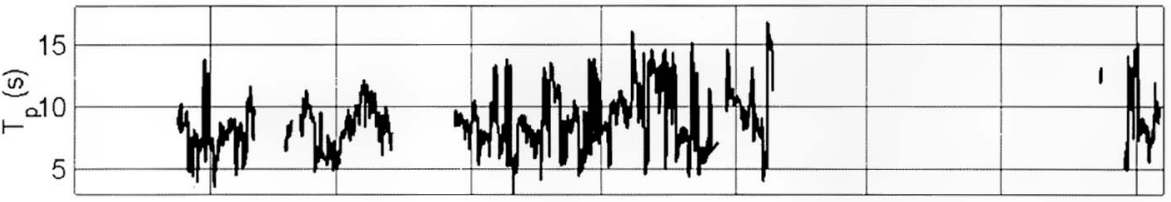

(d)

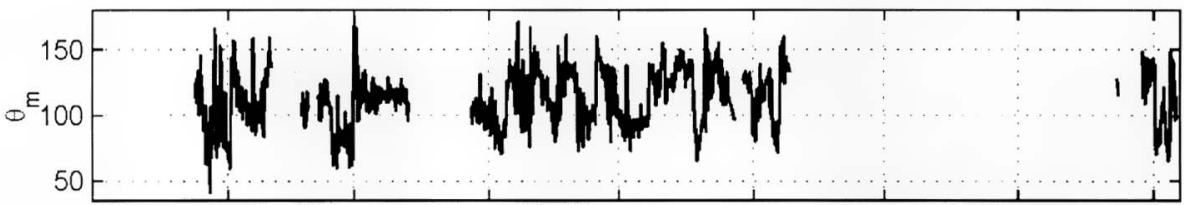

(e)

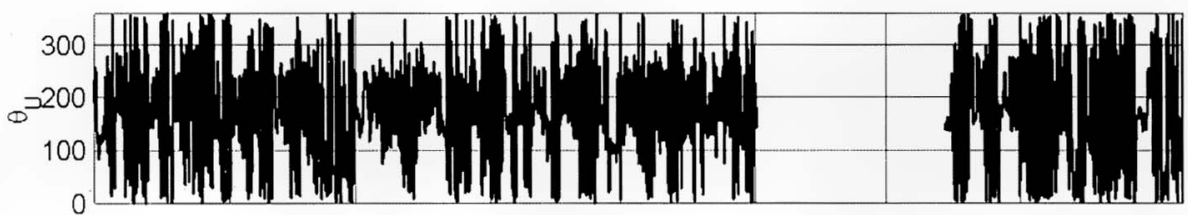

(f)

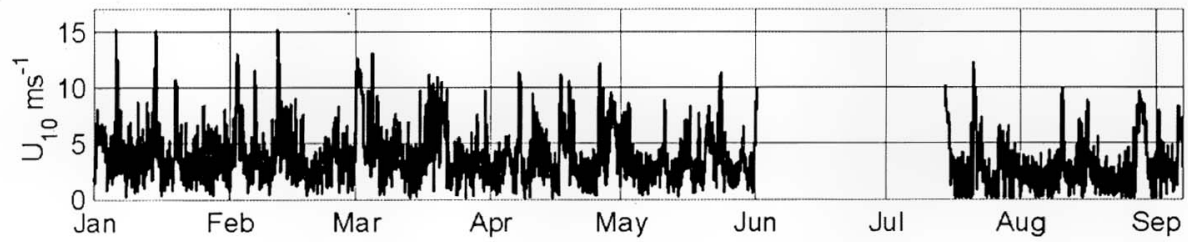

Fig. 2. Time series of (a) significant wave heights $H_{s}$, maximum wave heights $H_{\max }$, peak periods $T_{p}$, dominant directions $\theta_{m}$, wind directions $\theta_{U}$, wind speeds at 10 $\mathrm{m}$ height $U_{l 0}$. Both $\theta_{m}$ and $\theta_{U}$ follow the meteorological convention indicating arrival directions. 
From Figure 2(b) it is found that the maximum observed individual wave height $H_{\max }$ during the measurement period was $5.59 \mathrm{~m}$, corresponding to a maximum $H_{s}$ of $3.44 \mathrm{~m}$ [Fig. 2(a)]. Figure 2(c) records a maximum observed peak period $T_{p}$ of $16.67 \mathrm{~s}$, associated with the arrival of long traveled southeasterly swell. Mean values for the whole campaign were as follows: $H_{s}=1.02 \mathrm{~m}, T_{p}$ $=8.91 \mathrm{~s}$ and $\theta_{m}=112.41^{\circ}$.

Figure 3 shows joint plots of $\left[H_{s}\right.$ and $T_{p}$, [ $H_{s}$ and $\left.\theta_{m}\right],\left[T_{p}\right.$ and $\left.\theta_{m}\right]$ and histograms of $H_{s}, T_{p}$ and $\theta_{m}$. Contours in Figure 3, panels (a), (b) and (c), correspond to joint probability levels of .001, .005, $.01, .025, .05$ and .075 . The number of observations per class of joint values are also shown within the contour lines. The data shown in the histograms are organized into 25 classes.

In spite of the limitedness of our data set, it is possible to identify some general properties of the wave climate and, consequently, the main observed

(a)

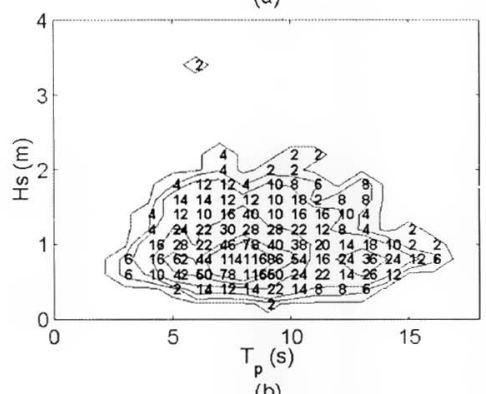

(b)

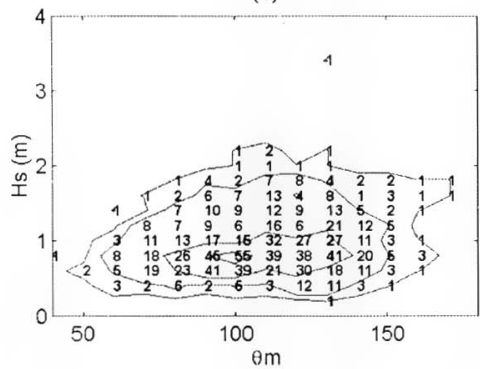

(c)

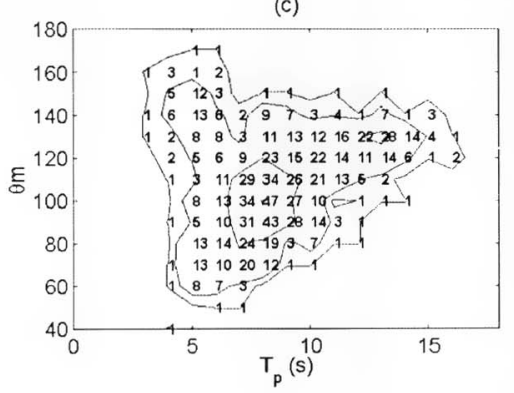

sea states. Figure 3(c) shows at least three different clusters of data with distinct joint peak period and directional properties. These clusters are centered in $\left[T_{p}=6 \mathrm{~s}\right.$ and $\left.\theta_{m}=140^{\circ}\right],\left[T_{p}=8 \mathrm{~s}\right.$ and $\left.\theta_{m}=100^{\circ}\right]$ and $\left[T_{p}=13 \mathrm{~s}\right.$ and $\left.\theta_{m}=130^{\circ}\right]$.

The cluster can also be seen in the histograms shown in Figure 3, panels (e) and (f), which quantify the relative frequency of $T_{p}$ and $\theta_{m}$. It is clear, for example, that most of the waves reaching the coast are predominantly from the east and southeast. The reasons for this are not only the constraints on direction due to the coastline orientation, but also the effects of refraction, that tends to reduce the directional range of incoming swell towards direction that is perpendicular to depth contours (Alves, 1996). The histogram corresponding to $T_{p}$ reveals finer details about the characteristics of the main sea states. Four clusters are seen at classes centered at $6,8,11$ and $13 \mathrm{~s}$.

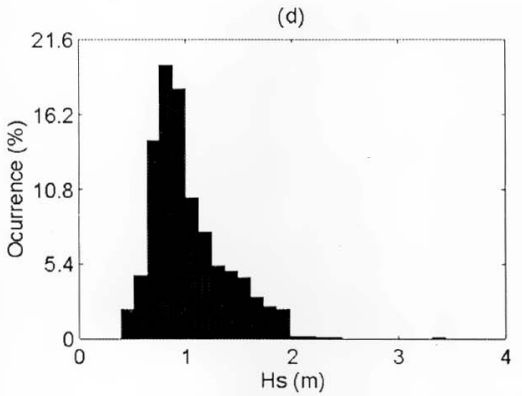

(e)
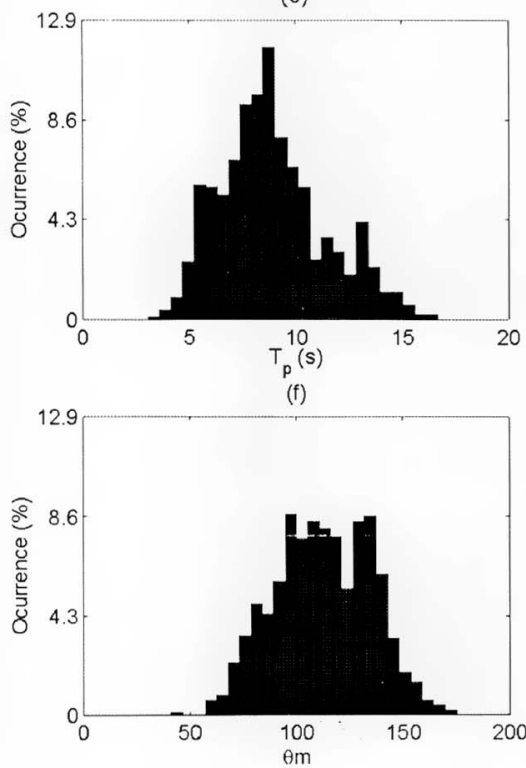

Fig. 3. Joint and individual distributions of wave climate parameters significant wave height $\mathrm{H}_{\mathrm{s}}$, peak period $T_{p}$ and dominant direction $\theta_{m}$. Panels corresponding to joint distributions of $H_{s}$ versus $T_{p}$ (a), $H_{s}$ versus $\theta_{m}$ (b), and $\theta_{m}$ versus $T_{p}$ (c) indicate contours with probability levels of $.001, .005, .01, .025, .05$ and .075 and number of occurences per class. Histograms in panels (d) to (f) show the percentage of occurrence of $H_{s}, T_{p}$ and $\theta_{m}$. 
Further indications for identifying the predominant sea states may be obtained by organizing the data into directional bins corresponding to five directions of origin: east-northeast $\left(40^{\circ} \leq \theta_{m} \leq\right.$ $\left.78.75^{\circ}\right)$, east $\left(78.75^{\circ}<\theta_{m} \leq 101.25^{\circ}\right)$, east-southeast $\left(101.25^{\circ}<\theta_{m} \leq 123.75^{\circ}\right)$, southeast $\left(123.75^{\circ}<\theta_{m} \leq\right.$ $\left.146.24^{\circ}\right)$ and south-southeast $\left(146.25^{\circ}<\theta_{m} \leq 180^{\circ}\right)$. Histograms of $H_{s}$ and $T_{p}$ for these directional bins are shown in Figure 4.

Combining the statistical information provided by the data set (Figs 3 and 4) with the knowledge of the typical wind patterns known to occur over the oceanic area that act as source of waves for the São Francisco do Sul coast, we identified four predominant sea-state patterns: (i) local wind seas from ENE; (ii) local wind seas from SSE; (iii) easterly waves; and (iv) southeasterly swell. The characteristics of each pattern will be presented and discussed next.

\section{East-northeast (ENE) wind seas}

East-northeast (ENE) seas were mainly observed during summer, accounting for approximately $10 \%$ of the overall observations. Peak periods varied typically in the range $3 \mathrm{~s}<$ $T_{p}<8 \mathrm{~s}$, while significant wave heights averaged $0.75 \mathrm{~m}$, ranging within $0.5 \mathrm{~m}<H_{s}<1.5 \mathrm{~m}$. Their generation was associated with the intensification of northeasterly winds at the boundary of the semi-permanent South Atlantic high pressure system. Intensification usually preceded the passage of frontal systems due to the development of strong pressure gradients over the study site. Figure 4, panels (a) and (b), shows the distributions of $T_{p}$ and $H_{s}$ associated with ENE wind seas.
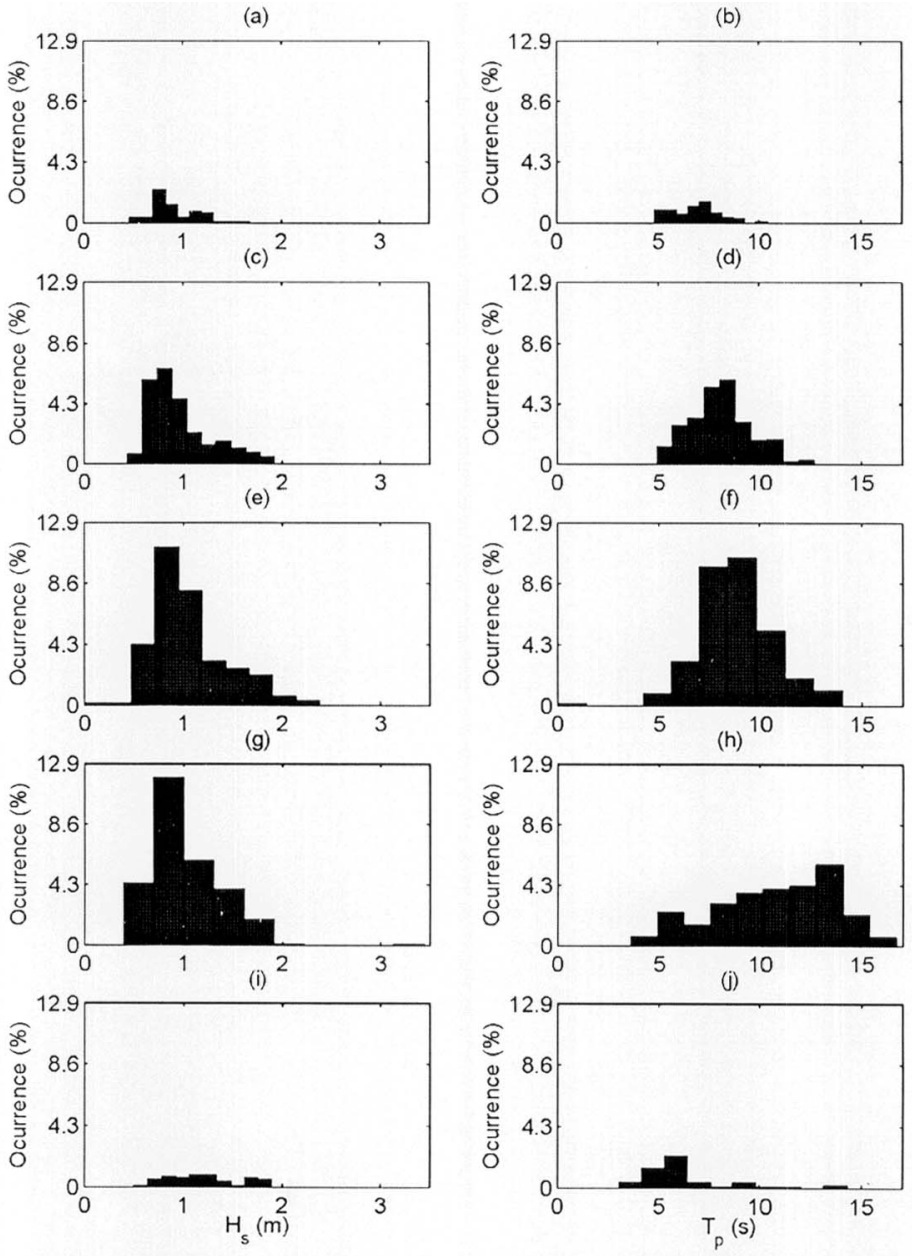

Fig. 4. Histograms of significant wave height $H_{s}$ and peak period $T_{p}$, divided into five directions of origin: (a) and (b) east-northeast $\left(40^{\circ}<\theta_{m} \leq\right.$ $\left.78.75^{\circ}\right)$; (c) and (d) east $\left(78.75^{\circ}<\theta_{m} \leq 101.25^{\circ}\right)$; (e) and (f) eastsoutheast $\left(101.25^{\circ}<\theta_{m} \leq 123.75^{\circ}\right) ;(\mathrm{g})$ and $(\mathrm{h})$ southeast $\left(123.75^{\circ}<\right.$ $\left.\theta_{m} \leq 146.24^{\circ}\right)$; and (i) and (j) south-southeast $\left(146.25^{\circ}<\theta_{m} \leq 180^{\circ}\right)$. 


\section{South-southeast (SSE) wind seas}

South-southeast (SSE) wind seas correspond to approximately $10 \%$ of the observed wave climate regimes. They were the most severe sea state in terms of significant wave heights, typical values ranging within $1 \mathrm{~m}<H_{s}<3.5 \mathrm{~m}$. Peak periods varied typically in the range $4 \mathrm{~s}<T_{p}<8 \mathrm{~s}$. In Figure 4 , the climatic characteristics of SSE seas appear mixed with those from southeasterly swell, since the histograms are grouped by directional ranges shared by both types of events. SSE seas would correspond to the lower $T_{p}$ and larger $H_{s}$ values in Figure 4, panels (g) to (j). The maximum observed value of $H_{s}$ $=3.44 \mathrm{~m}$ is associated with a SSE sea event that can be seen as a small contribution to the class centered at $3.25 \mathrm{~m}$ in Figure 4(g).

SSE seas are generated by winds caused by low-pressure systems carried along the coast by cold fronts. Due to the typical speed of progression of frontal systems and the associated pressure gradients, wind direction and intensity change very quickly within the area, as seen in Figure 5, panels (a) and (b). This fact results in the generation of a local wave field that has strong two-dimensional properties, as discussed by Alves \& Melo (1999). Figure 6(a) illustrates the passage of a cold front associated with SSE seas observed at the study site.

\section{Easterly waves}

Waves arriving from the east and southeast dominate the local wave climate (approximately 50\% of all observations), as seen in Figure 3 . As seen in Figure 4, panels (c) to (f), it is likely that waves from these two directional sectors belong to the same population, since both $T_{p}$ and $H_{s}$ have almost identical distributions. Therefore, they are grouped under the same pattern hereafter called easterly waves. The range of peak periods and significant wave heights observed during easterly wave events were typically within the ranges $6 \mathrm{~s}<T_{p}<11 \mathrm{~s}$ and $0.5 \mathrm{~m}<H_{s}<1.5 \mathrm{~m}$.

Figure 5, panels (c) and (d), shows the evolution of significant wave heights and peak periods of an easterly wave event. As the sea state builds up, conditions progress gradually from low values of peak periods corresponding with the local wind speed [Fig. 5, (e) and (f)], typical properties of wind seas, to peak periods well above those expected considering local winds only, thus indicating the gradual development of swell.

The evolution of easterly wave events is initiated by the passage of frontal systems. As the frontal systems propagate northward along the coast or move eastwards into the Atlantic Ocean, an anticyclone gradually moves north and becomes nearly stationary for several days, producing a lengthy and persistent easterly wind fetch off the study site. Such a meteorological scenario explains the characteristics observed in Figure 5, panels (c) to (f), resulting in easterly wind seas with short peak periods and small wave heights that dominate the initial stages of development, progressively evolving into larger waves that have properties of swell.
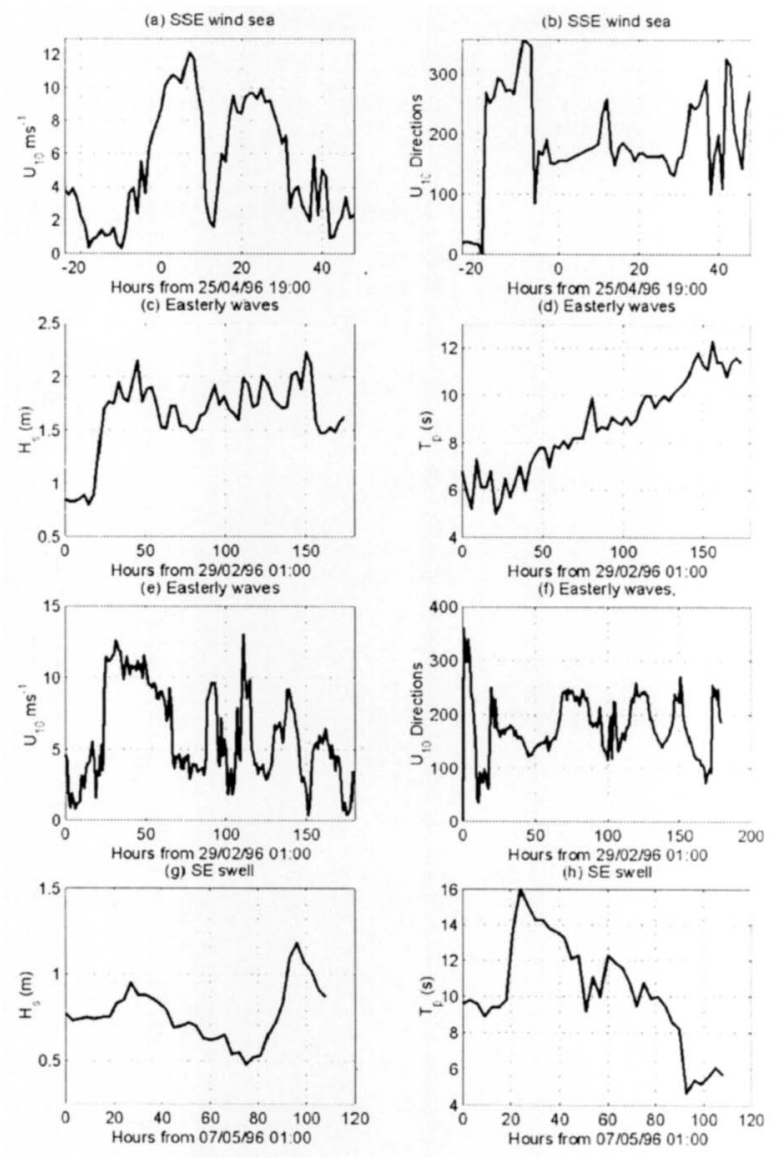

Fig. 5. Time series of wind and wave parameters corresponding to: (a) and (b) SSE wind sea; (c) to (f) easterly waves; and (g) and (h) SE swell. Wind properties of the SSE wind sea event shown in panels (a) and (b) were recorded around April 25. The wind and wave properties of the easterly waves event shown in panels (c) to (f) were observed beginning February 29. The wave properties from the SE swell event shown in panels $(\mathrm{g})$ and $(\mathrm{h})$ were recorded beginning May 7. The abscissa scales show the lags in hours from the indicated days and local times.

\section{Southeasterly swell}

Sea states associated with southeast directions [Fig. 4, panels (g) and (h)] have mainly swell properties: longer peak periods and no connection with the local wind speed or direction. In our data set, SE swell is the second most persistent feature of the local wave climate (approximately 25\% 
of the observations), presenting $T_{p}$ ranging from 7 to $16 \mathrm{~s}$ and $H_{s}$ varying between 0.5 and $2.0 \mathrm{~m}$.

Alves (1996) identifies two main sources of SE swell to the São Francisco do Sul coast. The first is associated with storms that sometimes propagate along the South American coast and deviate into the ocean within the $20^{\circ} \mathrm{S}$ and $40^{\circ} \mathrm{S}$ latitude band at distances in excess of $1000 \mathrm{~km}$ from the study site. Whenever these storms become slow moving systems, persistent southeasterly wind fetches develop along with strong pressure gradients as they migrate into areas dominated by warm air mass systems, resulting in strong wind fields.
The second swell sources are storms that migrate from the Southern Ocean northwards along the Argentinian coast near Patagonia, deviating towards the east into the Atlantic Ocean south of $40^{\circ} \mathrm{S}$. Figure $6(\mathrm{~d})$ shows part of one such storm centered over the Drake Passage, between the Antarctic Peninsula and the Falklands (Malvinas) Islands. The swell generated by this particular storm was observed at the São Francisco do Sul coast about three days after the peak of the storm and displayed the progressive decay in wave periods characteristic of the dispersive arrival of long traveled swell.

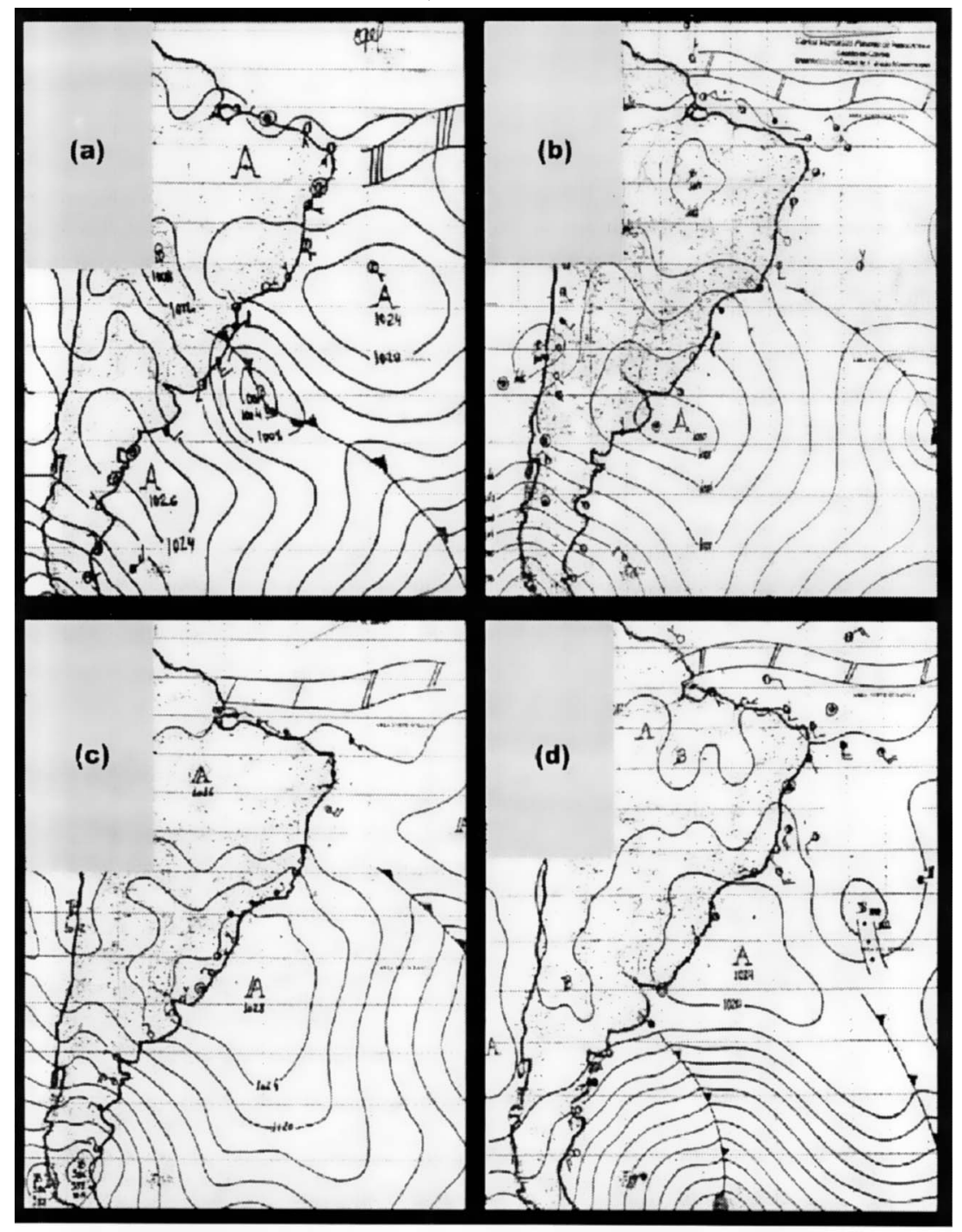

Fig. 6. Surface pressure charts [Diretoria de Hidrografia e Navegação (DHN), Brazilian Navy] indicating (a) the passage of a frontal system (diagonal line with triangles crossing the extra tropical low near the center of the panel) over the study site (25/04/96 12 h GMT); (b) and (c) a stationary high pressure system (labeled with the letter "A") expanding over the study site (26/04/96 $12 \mathrm{~h} \mathrm{GMT}$ and 27/04/96 $12 \mathrm{~h} \mathrm{GMT);} \mathrm{and} \mathrm{(d)} \mathrm{a} \mathrm{mid-latitude} \mathrm{storm}$ centered southeast from the Falkland Islands (the storm has closely spaced isobars forming a semi-circle at the bottom of the figure; 06/05/96 $12 \mathrm{~h}$ GMT). The study site is approximately in the center-point of each panel. 
In fact, Figure 5, panels (g) and (h), illustrates well the onset of the swell event mentioned above. Curiously, the arrival of this swell did not alter much the sea conditions in terms of $H_{s}$ [panel (g)], but caused a remarkable change in the peak period of the sea state [panel (h)]. After rising quickly to $16 \mathrm{~s}, T_{p}$ slowly decreased for the following hours. The dispersive arrival of swell systems generated by distant storms is one of the most conspicuous features of wind waves that have been reported since the pioneering contribution of Barber \& Ursell (1948) and Snodgrass et al. (1966). Melo \& Alves (1993) and Melo et al. (1995) used a similar approach to describe the arrival of long traveled swell to the Brazilian Coast.

A record of the time evolution of the peak period at a coastal station allows one to estimate the distance traveled by the incoming swell through a very simple calculation based on linear wave theory. Following Melo \& Alves (1993), the distance between São Francisco do Sul and the generating storm $\left(X_{s}\right)$ may be estimated by means of the expression:

$$
X_{s}=\frac{g}{4 \pi} \frac{\Delta t}{\Delta f_{p}} \approx \frac{g}{4 \pi}\left[\frac{T_{1} T_{2}}{T_{1}-T_{2}}\right] \Delta t
$$

where $g$ is the acceleration of gravity, $T_{1}$ and $T_{2}$ are the periods of swell components observed at times $t=$ 1 and $t=2$, respectively, $\Delta t$ is the elapsed time between the arrival of successive swell components and $\Delta f_{p}$ the difference between their peak frequencies $f_{p}=1 / T_{p}$.

Figure 5 provides an average value of $\Delta f_{p} /$ $\Delta t=2 \times 10^{-7} \mathrm{~s}^{-2}$. Plugging this into equation (7), one readily obtains a distance of $3900 \mathrm{~km}$ from the São Francisco do Sul coast, which is consistent with the approximate location of the southerly wind storm fetches seen in Figure 6(d) extending towards the Drake Passage.

\section{Transformation of wave spectra}

Theory and experiments have demonstrated that surface gravity waves are unaffected by the bottom whenever the depth of water is greater than approximately half the wavelength (see, for example, Dean \& Dalrymple, 1984). The depth at the measurement site in São Francisco do Sul was about $20 \mathrm{~m}$. Thus, it is expected that spectral components representing lengths equal to or smaller than approximately $40 \mathrm{~m}$, which correspond to waves with periods less than about $6 \mathrm{~s}$ to $7 \mathrm{~s}$, would not "feel" the bottom.

This being so, short period wind seas will remain unaffected by refraction over bottom topography as they propagate from deeper waters towards the measurement site. Consequently, the majority of spectra associated with ENE and SSE wind seas may be directly extrapolated to surrounding areas with depths greater than $20 \mathrm{~m}$. The wave field at shallower positions may be determined through a forward spectral refraction model, using the measured spectrum as initial/boundary conditions.

Easterly waves and SE swell with considerable energy in period bands longer than $6 \mathrm{~s}$ are expected to undergo transformation by bottom refraction before reaching the measurement site, rendering a direct extrapolation of the measured wave field to surrounding areas invalid. This limitation may be overcome through a two-step technique using numerical propagation models. The first step consists in estimating the spectra in deep waters, where the wave field should be spatially homogeneous, by backrefracting the measured shallow-water spectra. As a second step, the deep-water spectra are forwardrefracted to provide the desired extrapolation of the actual measurements to a regional scale.

Longuet-Higgins $(1955,1956)$ showed that for linear waves the energy initially concentrated around an arbitrary range of the directional windwave spectrum keeps itself bound to the same frequency throughout the entire refraction process. Therefore, it is possible to establish a direct relationship between the energy density of an initially undisturbed spectral component $E_{0} \quad\left(f, \theta_{0}\right)$ and the refracted energy density $E(f, \theta)$, as long as dissipation, diffraction and nonlinear processes are negligible.

The governing equation relating initial and refracted spectra is

$$
E(f, \theta)=\frac{k}{k_{0}} \frac{\mathcal{c}_{g 0}}{\mathcal{c}_{g}} E_{0}[f, \Gamma(f, \theta)]
$$

where the directional spectrum $E(f, \theta)$ is defined in terms of components with frequency $f$, direction of propagation $\theta$, wave number $k$ and group velocity $c_{g}$. The subscripts 0 denote properties related to the spectrum before refraction. Wave numbers and group velocities of any given component are related to its frequency through the linear dispersion relation

$$
\omega^{2}=g k \tanh (k h)
$$

where $\omega=2 \pi f, k=2 \pi / \mathrm{L}$ is the wavenumber and $h$ is the local water depth.

The gamma function $\Gamma(f, \theta)$ relates initial and refracted directions, as follows

$\theta_{0}=\Gamma(f, \theta)$ 
Equation (8) is valid along a ray path. For an orthogonal Cartesian frame, rays are defined by the following equations (Munk \& Arthur, 1951)

$$
\left\{\begin{array}{l}
\frac{d x}{d t}=c_{g} \cos \theta \\
\frac{d y}{d t}=c_{g} \operatorname{sen} \theta \\
\frac{d \theta}{d t}=\frac{d c_{g}}{d x} \operatorname{sen} \theta-\frac{d c_{g}}{d y} \cos \theta
\end{array}\right.
$$

The present study uses a numerical model based on equations (8) to (11) to calculate the deep water spectra $E_{0}\left(f, \theta_{0}\right)$ from the measured shallowwater spectra $E(f, \theta)$. Since the procedure is done in reverse order from the actual wave propagation sense (which is deep-to-shallow water), it is called back or inverse refraction. Techniques based on equation (8) are also called spectral mapping (O'Reilly, 1991; O'Reilly \& Guza, 1998).

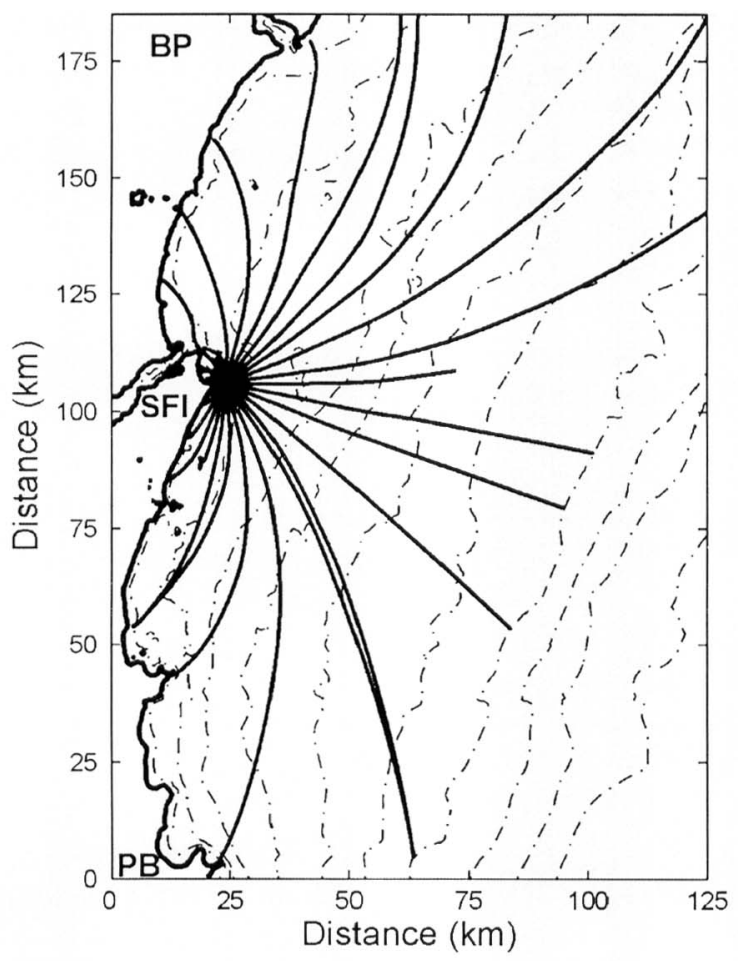

Fig. 7. Diagram showing the fan of back-refracted ray paths departing from the measurement location. This example shows the back-refracted rays of a spectral component with $f=0.05 \mathrm{~Hz}$. Only rays that reach deep water are retained in the computations (i.e., rays reaching land boundaries are eliminated). Also shown are the depth contours from $10 \mathrm{~m}$ to $100 \mathrm{~m}$ at a $10 \mathrm{~m}$ interval (dash-dotted lines) and the following key geographical landmarks, from top to bottom: Parangua Bay (BP), São Francisco do Sul Island (SFI) and Porto Belo (PB).
The practical application of this procedure is as follows. For any given frequency, one performs the back-refraction of a set of equally spaced rays (the "ray fan") within a range of directions pointing offshore all departing from the measurement site and ending at the corresponding deep water depth. Figure 7 illustrates such a result for the São Francisco do Sul coast for a component with frequency of $0.05 \mathrm{~Hz}$. The tracing of rays allows the construction of the function $\Gamma(f, \theta)$, which maps the shallow-water directions $\theta$ of all spectral components resolved in the model into their deep-water unrefracted directions $\theta_{0}$. Values of $\theta_{0}=\Gamma(f, \theta)$ are obtained through integration of the ray equations (11). Further details of these calculations are found in Alves (1996).

The extrapolation of the estimated deepwater spectrum to the surroundings of the measurement site is computed by a simple forwardpropagation model, based on two other properties derived from refraction theory, namely, the wave number irrotationality and the energy flux conservation conditions. For a continental shelf with smooth bottom contours (as in São Francisco do Sul) and in the absence of significant currents, changes in the wave number vector $\boldsymbol{k}$ of any given spectral component may be calculated by applying the wave number irrotationality condition, which reads

$$
\nabla \times \boldsymbol{k}=0
$$

where $\nabla$ stands for the horizontal gradient operator.

The associated wave height variations due to refraction are calculated through the energy flux conservation equation

$$
\nabla \cdot\left(c_{g} E\right)=0
$$

where $E(f, \theta)$ is the energy density of an arbitrary spectral component.

The spectral forward-refraction model used in the present study is a spectral version of the monochromatic wave refraction model presented in Dalrymple (1988). The model solves numerically the coupled system of equations (12) and (13), allowing the use of grids covering large areas. Details of the numerical solution method are presented in the Appendix. Further information may be found in Alves (1996).

Before applying the model to a real case, two tests were made to assess the performance of the forward-propagation model. The first test compared the analytical solution of monochromatic wave propagation with several angles of incidence over a beach with plane parallel depth contours (see Dean \& Dalrymple, 1984) to the model calculations. 
Throughout all these preliminary test cases (not shown) the model reproduced the exact analytical solution (Alves, 1996).

The second test compared the model results with those from a laboratory experiment described in Mase \& Kirby (1992). In this test case, a twodimensional wave field defined by a frequencydirection wave spectrum was propagated over a beach with plane parallel depth contours. An algorithm to calculate wave breaking based on statistical properties of the wave field as proposed by Thornton \& Guza (1983) was included in the forward-refraction model to provide the energy decay within the surf zone.

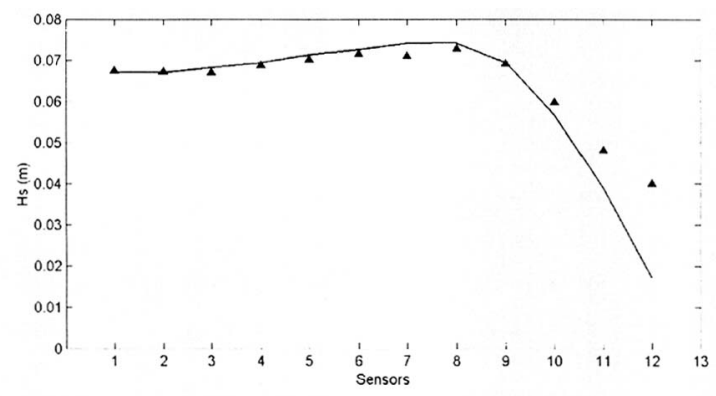

Fig. 8. Comparison between laboratory results from Mase \& Kirby (1992) (triangles) and model calculation (continuous line).

The model validation made at 12 equally spaced points along the domain in the $x$ direction is summarized in Figure 8. Before the onset of breaking (locations 1 to 8 ) experiment and model agree with less than $5 \%$ relative error. The agreement is still good at locations $9(0.43 \%)$ and $10(5.02 \%)$, but becomes progressively poorer inside the breaking zone, probably due to non-linear effects not included in the model. Since our simulations exclude the breaking zone, these results indicated that the model was adequate for the present purposes.

\section{Impact of refraction on spectral transformation}

Four observed frequency-direction spectra, representing different stages of a SE swell event recorded at the measurement site on September 1996, were initially used to assess the impact of refraction on the propagation of swell spectra. Using the raytracing inverse-refraction model described in the previous section, deep-water spectra were obtained for each of the four cases considered: the initial, two intermediate and the final stages of the SE swell event. All spectra were discretized into 12 frequency bands with 30 directional bins each and a rectangular $186 \mathrm{~km}$ by $185 \mathrm{~km}$ grid with $\Delta x=\Delta y=250 \mathrm{~m}$ was used in the calculations.
Figure 9 shows an example of the differences between the measured shallow water onedimensional spectrum at an intermediate stage of the event and its corresponding deep water estimate. The remarkable difference seen in the energy levels around the peak frequency indicates the importance of refraction for this case. Considering the four cases, the differences in significant wave height between shallow and deep water were always greater than $20 \%$. Directional computations (not shown) also caused transformations in the main direction $\theta_{m}$ in excess of $20^{\circ}$ (Alves, 1996).

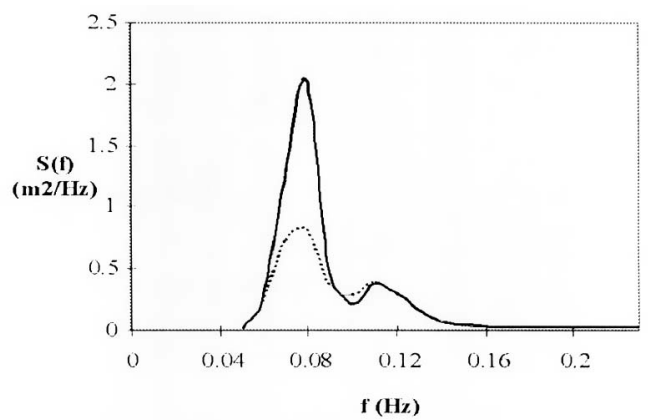

Fig. 9. Shallow- (dashed line) and deep-water (continuous line) frequency spectra illustrating the transformation due to refraction of a $\mathrm{SE}$ swell event observed on May 8, 1996, at 7 AM local time.

The four deep-water swell spectra were then used as initial conditions for the forward propagation model, yielding sea-state predictions that covered the whole northern coast of Santa Catarina state. A new rectangular depth grid with $136 \mathrm{~km}$ ( $x$ direction) by $185 \mathrm{~km}$ ( $y$ direction) and $\Delta x=\Delta y=250 \mathrm{~m}$ was used in the forward-refraction computations. As a check for the full methodology, the forward-propagated spectra predicted at the location where the waverider was deployed (see Fig. 1) were compared to the original measured spectra. This might seem an obvious comparison. However, this is not the case. Although both back- and forward-refraction models are based on similar general physical assumptions, they are developed using different mathematical approaches, as outlined in section 4 .

Measured and numerically reconstructed directional one-dimensional frequency spectra were in very good agreement, with differences in $H_{s}$ of less than $4 \%$. Figure 10 shows this comparison for the case with strongest refraction effects, observed on May 8th, 1996, 7AM local time. A comparison between measured and computed directional slices of the two-dimensional frequency-direction spectrum at the spectral peak frequency $E\left(f_{p}, \theta\right)$ is presented in Figure 11 for the same test case. This figure 
demonstrates that the calculated directional distribution reproduced remarkably well the unsmoothed measured distribution, calculated using the maximum entropy technique described in Alves \& Melo (1999).

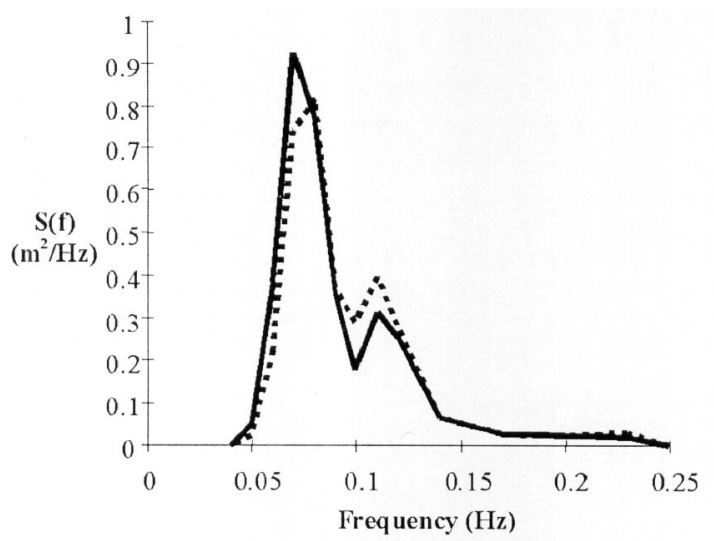

Fig. 10. Comparison between measured (continuous line) and calculated (dashed line) frequency spectra for swell waves recorded on May 8, 1996, 7 AM local time.

The same back- and forward-refraction approach was applied to assess the impact of refraction on the propagation of selected spectra from locally-generated ENE and SSE wind-seas and easterly waves. Overall results are summarized in Table 1. The degree of transformations due to refraction and shoaling were assessed in terms of observed and computed significant wave heights $H_{s}$ and main directions $\theta_{m}$, indicated respectively in Table 1 by superscripts obs and $d w$.

Other parameters listed in Table 1 for each selected event are the type of sea-state pattern, the date and time of its observation, the spectral peak period $T_{p}$, the percentage difference $\Delta H_{s}$ between $H_{s}{ }^{o b s}$ and $H_{s}^{d w}$ relative to $H_{s}^{d w}$ and the absolute difference in degrees $\Delta \theta_{m}$ between $\theta_{m}{ }^{\text {obs }}$ and $\theta_{m}{ }^{d w}$. Diagnostic parameters indicating the degree of transformations due to refraction and shoaling are the variations $\Delta H_{s}$ and $\Delta \theta_{m}$.

The negligible effects of refraction on locally generated wind seas are illustrated by the first two cases listed in Table 1, corresponding to SSE and ENE, seas respectively. As expected, variations in wave height and direction are under $5 \%$ and $5^{\circ}$, both lower than typical instrumental errors or sampling variability effects (see e.g., Krogstad, 1991; Donelan \& Pierson, 1987 and Allender et al., 1989).
Transformations due to refraction were also negligible during the easterly waves events listed in Table 1. Variations in wave height and direction were under $5 \%$ and $5^{\circ}$, despite their longer measured peak periods. This can be explained by the fact that easterly waves propagate in directions that are approximately perpendicular to the smooth depth contours that characterize the bottom topography offshore from the study site. Consequently, refraction of easterly waves is negligible due to the absence of depth gradients along crests of individual wave components of this sea-state pattern. Although shoaling still occurs closer to the shoreline, it was not a noticeable effect at the depth in which the measurements were made.

The four cases of SE swell listed in Table 1 were associated with a single long traveled swell event, as discussed previously in this section. The evolution of this event illustrates well how the combined values of $\mathrm{Tp}$ and $\theta_{m}$ determine the magnitude of transformations due to refraction, indicated by the resulting values of $\Delta H_{s}$ and $\Delta \theta_{m}$

When the SE swell event first becomes noticeable the periods are high $(16.67 \mathrm{~s})$ and the measured waves propagate from SE. In deep water the computed direction is shifted by $14^{\circ}$ towards SSE. Wave heights decrease by approximately $20 \%$ as the waves propagate from deep water towards the observation point. As the event evolves in time, the peak periods fall progressively with a corresponding weakening of the transformation process, until this transformation becomes negligible with the variations falling within typical values of instrumental errors.

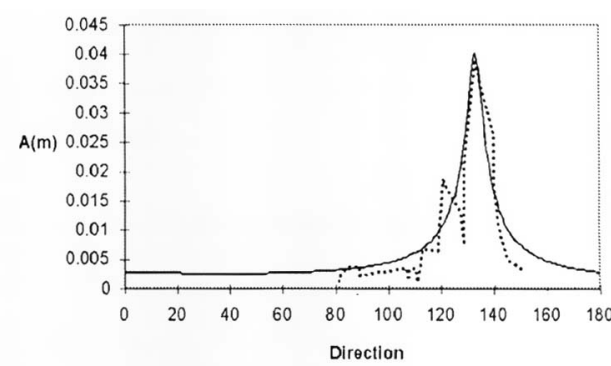

Fig. 11. Directional distribution of amplitudes at the peak frequency from a spectrum measured on May 8, 1996, at 7 AM. Shown are the unsmoothed measured spectrum (continuous line) and the spectrum calculated by the wave model (dashed line). 
Table 1. Effects of refraction on significant wave height $H_{s}$ and peak periods $\mathrm{T}_{\mathrm{p}}$ of selected occurences of local wind seas, swell and easterly waves. Measurements are indicated as $H_{s}{ }^{o b s}, T_{p}$ and $\theta_{m}{ }^{o b s}$. Deep-water values computed with an inverse refraction model are indicated as $H_{s}{ }^{d w}$ and $\theta_{m}{ }^{d w}$. The percentage variation of $H_{s}$ is indicated by $\Delta H_{s}=\left(H_{s}^{o b s}-H_{s}^{d w}\right) / H_{s}^{d w}$ and the absolute variation in propagation angles by $\Delta \theta_{m}=\theta_{m}{ }^{\text {ohs }}-\theta_{m}{ }^{d w}$.

\begin{tabular}{lccccccccc}
\hline $\begin{array}{l}\text { Type of } \\
\text { Event }\end{array}$ & Date & Time & $\begin{array}{c}\mathrm{T}_{\mathrm{p}} \\
(\mathrm{s})\end{array}$ & $\begin{array}{c}\mathrm{H}_{\mathrm{s}}{ }^{\mathrm{obs}} \\
(\mathrm{m})\end{array}$ & $\begin{array}{c}\mathrm{H}_{\mathrm{s}}{ }^{\mathrm{dw}} \\
(\mathrm{m})\end{array}$ & $\begin{array}{c}\Delta \mathrm{H}_{\mathrm{s}} \\
(\%)\end{array}$ & $\theta_{\mathrm{m}}{ }^{\text {obs }}$ & $\theta_{\mathrm{m}}{ }^{\mathrm{dw}}$ & $\Delta \theta_{\mathrm{m}}$ \\
\hline SSE sea & $25 / 04 / 96$ & $22: 00$ & 5.88 & 1.38 & 1.45 & -4.83 & $159^{\circ}$ & $162^{\circ}$ & $-3^{\circ}$ \\
ENE sea & $01 / 02 / 96$ & $04: 00$ & 6.67 & 0.59 & 0.62 & -4.84 & $71^{\circ}$ & $73^{\circ}$ & $2^{\circ}$ \\
Easterly & $01 / 03 / 96$ & $22: 00$ & 7.14 & 1.67 & 1.74 & -4.02 & $95^{\circ}$ & $93^{\circ}$ & $2^{\circ}$ \\
Easterly & $03 / 03 / 96$ & $22: 00$ & 8.60 & 1.63 & 1.70 & -4.12 & $103^{\circ}$ & $104^{\circ}$ & $-1^{\circ}$ \\
SE swell & $08 / 05 / 96$ & $01: 00$ & 16.67 & 0.69 & 0.83 & -16.87 & $131^{\circ}$ & $145^{\circ}$ & $-14^{\circ}$ \\
SE swell & $08 / 05 / 96$ & $07: 00$ & 14.29 & 0.76 & 0.92 & -17.39 & $130^{\circ}$ & $141^{\circ}$ & $-11^{\circ}$ \\
SE swell & $08 / 05 / 96$ & $22: 00$ & 12.50 & 0.57 & 0.65 & -12.31 & $134^{\circ}$ & $142^{\circ}$ & $-8^{\circ}$ \\
SE swell & $09 / 05 / 96$ & $10: 00$ & 10.00 & 0.50 & 0.54 & -7.41 & $113^{\circ}$ & $112^{\circ}$ & $1^{\circ}$ \\
\hline
\end{tabular}

\section{Concluding Remarks}

This study presents a preliminary investigation of the wind-wave climate and its transformation off São Francisco do Sul island, at the northern coast of the Santa Catarina state, using directional measurements of wind-wave spectra made during the year of 1996. Analyses of joint distributions of $H_{s}, T_{p}$ and $\theta_{m}$, combined with a study of the typical wind patterns found over the South Atlantic Ocean allowed the identification of the following four major sea states and associated meteorological conditions:

- $\quad$ East-northeast (ENE) wind seas;

- South-southeast (SSE) wind seas;

- Easterly waves;

- Southeasterly swell.

Transformations of these main sea-state patterns due to refraction and shoaling are investigated through a numerical modeling approach that allows the reconstruction of the wave field within extensive coastal areas, using single point measurements of the wave spectrum in shallow waters. The methodology consists of first estimating deep-water spectra using an inverse-refraction model, initialized with observed shallow water spectra. The wave field is then reconstructed within an extense area around the measurement site using a forward-refraction model. A comparison between measured and reconstructed spectra at the deployment site yielded consistent results, suggesting that the proposed methodology works well for the São Francisco do Sul coast.
A summary of results concerning the transformation of the main sea states due to depth induced refraction and shoaling is presented. This final summary presents selected cases representative of the four major sea states, allowing a first assessment of the general characteristics and magnitudes of wave climate transformations in the northern coast of Santa Catarina, Brazil.

In closing, we wish to point out that the ideal test for the wave transformation methodology presented herein would be to compare the estimated deep water spectra with actual deep water measurements. That, of course, would require simultaneous measurements of directional wave spectra at a shallow and a deepwater site which, unfortunately, exceeded our economical and logistical possibilities at the time. Although the difficulties involved in such a double measurement operation are still very challenging, this remains as a goal to be achieved in our future work.

\section{APPENDIX}

\section{Forward refraction model}

The forward spectral wave refraction model developed by Alves (1996) and used in the present study is based on the technique described in Dalrymple (1988) to study monochromatic waves. The spectral model version solves the coupled system of equations (12) and (13) explicitly using a finite difference method. The numerical solution uses a discretization module shifted in the $y$ direction, resembling a zig-zag shape (Fig. 12). 


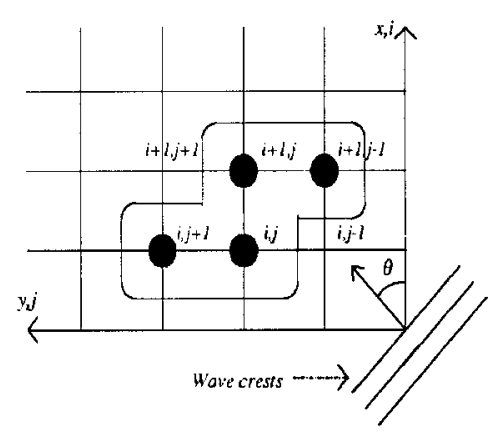

Fig. 12. Detail of the numerical mesh and of the discretization module. The slashes on the lower right corner illustrate wave crests and the angle of propagation.

The solution progresses in $y$ from left to right or vice-versa, depending on the initial direction $\theta$ of each component at the outer boundary (in this appendix, azimuthal directions used throughout the paper are converted into grid directions referenced to the westward-pointing $x$ axis). The whole spectrum is solved after the discretization module has swept all grid points for a fixed $x$ position. The solution progresses in the cross-shore $x$ direction line by line.

For a Cartesian system of reference, equation (12) is rewritten as

$$
\frac{\partial \alpha_{n}}{\partial x}-\frac{\partial \beta_{n}}{\partial y}=0
$$

where $\alpha_{n}=k_{y}=k_{n} \sin \theta_{n}$ and $\beta_{n}=k_{y}=k_{n} \cos \theta_{n}$ are the orthogonal projections of the wave number modulus $k_{n}$. For the sake of simplicity, the subscript $n$, identifying an arbitrary component of the wave spectrum $E(f, \theta)$, will be dropped hereafter. By definition, $\beta$ can be related to $\alpha$ by

$$
\beta=\left(k^{2}-\alpha^{2}\right)^{1 / 2}
$$

The wave number modulus is related to the frequency by the dispersion relation $\omega= \begin{cases}g k & k\end{cases}$ $\tanh (k h)\}^{1 / 2}$, where $g$ is the acceleration due to gravity and $h$ is the local water depth. Therefore, the wave number is calculated directly from the frequency at each grid point considering only the local depth.

Equation (14) is discretized using central differences along the $x$ and $y$ axis, with equally spaced intervals $\Delta x$ and $\Delta y$. The partial differentials in $x$ are solved at an intermediate point $(i+1 / 2, j)$. The resulting expressions for the $x$ and $y$ partial derivatives are

$$
\left(\frac{\partial \beta}{\partial y}\right)=r\left[\beta_{i, j+1}-\beta_{i, j}+\beta_{i+1, j}-\beta_{i+1, j-1}\right]
$$

and

$\alpha_{i+1, j}=\alpha_{i, j}+\left(\frac{\partial \beta}{\partial y}\right)$

where $r=\Delta x / 2 \Delta y$. Using the relation (15) it is possible to eliminate the $\beta$ terms with subscript $(i+1, j)$, which identify unknown quantities. After some algebra, the resulting expression is

$\alpha_{i+1, j}^{2}+2 b \alpha_{i+1, j}+c=0$

where

$b=\frac{r\left(\beta_{i+1, j-1}-\beta_{i, j+1}+\beta_{i, j}\right)-\alpha_{i, j}}{1+r^{2}}$

and

$c=\frac{\left[\left(1+r^{2}\right) b\right]^{2}-r^{2} k_{i+1, j}^{2}}{1+r^{2}}$

The positive root of equation (18) gives the solution for the $\alpha$ terms at each new grid point as the solution progresses in space. The $\beta$ terms are obtained directly through the relation (15). The angle of propagation at each grid point is, therefore

$\theta_{i, j}=\tan ^{-1}\left(\frac{\alpha_{i, j}}{\beta_{i, j}}\right)$.

The numerical solution of the energy conservation equation (13) is obtained similarly. Using equation (14), now with $\varepsilon=E c_{g} \cos \theta$ and $\phi=$ $-E c_{y} \sin \theta$, the resulting expressions to be solved are

$$
\varepsilon_{i+1, j}=\frac{\varepsilon_{i, j}+r\left(\phi_{i+1, j-1}-\phi_{i, j+1}+\phi_{i, j}\right)}{1+r\left(\operatorname{sen} \theta_{i+1, j} / \cos \theta_{i+1, j}\right)}
$$

and

$\phi_{i+1, j}=\varepsilon_{i+1, j}\left(\frac{\operatorname{sen} \theta_{i+1, j}}{\cos \theta_{i+1, j}}\right)$

where the group velocity is given by 


$$
c_{g}=\frac{d \omega}{d k}=\frac{g}{2 k} \tanh (k h)\left(1+\frac{2 k h}{\operatorname{senh}(2 k h)}\right)
$$

The numerical model outputs amplitude and angle of propagation of individual spectral components. Since the entire spectrum is solved progressing line by line toward the $x$ direction, it is also possible to compute statistical parameters of the wave field at each grid point. The main parameter used for applications is the significant wave height $H_{s}$, obtained from the model calculations through the expression

$$
H_{s}=\left[2 \sum\left(H_{n}\right)_{i, j}^{2}\right]^{1 / 2}
$$

where the wave height $H_{n}$ of individual components is defined as

$\left(H_{n}\right)_{i, j}=\frac{8\left(\varepsilon_{n}\right)_{i, j}}{c_{g} \cos \left(\theta_{n}\right)_{i, j}}$

and $\varepsilon$ is the energy flux in the $x$ direction (equation 22).

\section{Acknowledgements}

The authors are grateful to Dr. William O'Reilly for providing the inverse refraction code. We also thank Davide Franco, Nei Seixas, Renato Martins, Cesar Ribeiro and Eliane Truccollo for providing technical support and a proper scientific environment for discussions that much enriched the contents of this manuscript. This study was made possible through the financial support and research grants provided by PETROBRAS and Conselho Nacional de Desenvolvimento Científico e Tecnológico (CNPq).

\section{References}

Allender, J.; Audunson, T.; Barstow, S. F.; Bjerken, S.; Krogstad, H. E.; Steinbakke, P.; Vartdal, L.; Borgman, L. \& Graham, C. 1989. The WADIC Project: a comprehensive field evaluation of directional wave instrumentation. Ocean Engng., 16(5-6):505-536.

Alves, J. H. G. M. 1991. Considerations on the arrival at the Rio de Janeiro coast of South Pacific swell propagating through the Drake Passage. Bachelor of Oceanography Final Monograph. Rio de Janeiro State University (UERJ), Oceanography Department. $71 \mathrm{p}$. (in Portuguese).
Alves, J. H. G. M. 1996. Refraction of wind-wave spectra in shallow waters: Applications to the Coast of São Francisco do Sul, SC, Brazil. M.Sc. Thesis. Federal University of Santa Catarina (UFSC), 89p. (in Portuguese).

Alves, J. H. G. M. \& Melo, E. 1999. On the measurement of directional wave spectra at the Southern Brazilian coast. Appl. Ocean. Res., 21(6):295-309.

Barber, N. F. \& Ursell, F. 1948. The generation and propagation of ocean waves and swell. Phil. Trans. R. Soc., A240(824):527-560.

Dalrymple, R. A. 1988. Model for refraction of water waves. J. Watway Port. coast. Ocean Engng., 114(4):423-435.

Dean, R. G. \& Dalrymple, R. A. 1984. Water wave mechanics for engineers and scientists. $4^{\text {th }}$ ed. Singapore, World Scientific. 353p.

Donelan, M. A. \& Pierson, W. J. 1987. Radar scattering and equilibrium ranges in windgenerated waves with application to scatterometry. J. geophys. Res., 92(C5):49715029.

Krogstad, H. E. 1991. Reliability and resolution of directional wave spectra from heave, pitch and roll buoy wave data. In: Beal, R. C. ed. Directional ocean wave spectra. Baltimore, The Johns Hopkins University Press. p.66-71.

Lima, L. C. E. \& Satyamurti, H. E. 1992. An observational study of formation and trajectory of extratropical cyclones in South America. In: BRAZILIAN CONGRESS OF METEOROLOGY, 7. Rio de Janeiro, 1992. Proceedings. Rio de Janeiro, SBMet., 2:706710.

Longuet-Higgins, M. S. 1952. On the statistical distribution of heights of sea waves, J. mar. Res., 11:245-266.

Longuet-Higgins, M. S. 1955. The refraction of sea waves in shallow water, J. Fluid. Mech., 1:163176.

Longuet-Higgins, M. S. 1956. On the transformation of a continuous spectrum by refraction. Proc. Cambridge Phyl. Soc., 53(1):226-229. 
Longuet-Higgins, M. S.; Cartwright, D. E. \& Smith, N. D. 1963. Observations of the directional spectrum of sea waves using the motions of a floating buoy. In: Admiral, R. \& Stephan, E. C. eds. Ocean wave spectra. New Jersey, Pretice-Hall. p.111-136.

Mase, H. \& Kirby, J. T. 1992. Modified frequencydomain $\mathrm{KdV}$ equation for random wave shoaling. Proc. $23^{\text {rd }}$ ICCE, ASCE, p.474-487.

Melo, E. \& Alves, J. H. G. M. 1993. A note on the arrival of long traveled swell at the Brazilian Coast. In: SIMPÓSIO BRASILEIRO DE RECURSOS HÍDRICOS, 10. Gramado, 1993. Proceedings. Porto Alegre, UFRGS/ABRH, 5:362-369.

Melo, E. 1995. Instrumental confirmation of the arrival of North Atlantic swell to the Ceara coast. In: INTERNATIONAL CONFERENCE COASTAL AND PORT ENGINEERING IN DEVELOPING COUNTRIES. COPEDEC, 4. Rio de Janeiro, 1995. Proceedings. Rio de Janeiro, ABRH, 3: 1984-1996.

Munk, W. H. \& Arthur, R. S. 1951. Wave intensity along a refracted ray. Scripps Institute of Oceanography Wave Report, 95, Ref. 51-7. $18 \mathrm{p}$.
Nimer, E. 1989. Climatology of Brazil. Rio de Janeiro, IBGE, Natural Resources and Environmental Studies Departament. $421 \mathrm{p}$. (in Portuguese)

O'Reilly, W. 1991. Modeling surface gravity waves in the Southern California Bight. $\mathrm{PhD}$ Thesis. San Diego, Scripps Institute of Oceanography/UCSD. 89p.

O'Reilly, W. \& Guza, R. T. 1998. Assimilating coastal wave observations in regional swell predictions. Part 1: Inverse methods. J. phys. Oceanogr., 28(4):679-691.

Snodgrass, F. E.; Groves, G. W.; Hasselmann, K. F.; Miller, G. R.; Munk, W. H. \& Powers, W. M. 1966. Propagation of swell across the Pacific. Phil. Trans. R. Soc., A259(1103):431-497.

Taljaard, J. J. 1967. Development, distribution and movement of cyclones and anticyclones in the Southern Hemisphere during the IGY. J. appl. Met., (6):973-987.

Thornton, E. B. \& Guza, R. T. 1983. Transformation of wave height distribution. J. geophys. Res., 88(C10):5925-5938.

(Manuscript received 27 March 2001; revised 18 October 2001; accepted 12 December 2001) 